\title{
Knowledge, attitude and implementation of evidence-based practice of physiotherapists in India: A web-based cross-sectional study
}

\author{
Rekha Chaturvedi, Shaveta Khrolia, Vandana Yadav, Meenakshi Bagri, Jyoti
}

Guru Jambheshwar University of Science and Technology, Hisar, Haryana, India

\begin{abstract}
Background and objective. Evidence based practice (EBP) is based on the combination of the best research finding and clinical skill to ease clinical decision-making procedure. Patients treated with evidence-based practices have much better results as compared to the other patients. In today's world, EBP has attained global acceptance in physiotherapy sector. The objective of the study was to access the knowledge, attitude and implementation of EBP of physiotherapists in India via a cross sectional study.

Method. A cross sectional survey was held with the help of a web based customized questionnaire and was sent to physiotherapists.

Results. Most of the subjects were affirmative regarding EBP but did not have enough knowledge and expertise for its implementation. The chief barriers for EBP implementation was lack of time and the cost of information resources.

Conclusions. Physiotherapists need to upgrade their perspective, knowledge, understanding and skills regarding EBP. Furthermore, EBP must be added to the academic curriculum for its early recognition among the medical students.
\end{abstract}

Keywords: evidence based practice, physiotherapists, barriers, clinical findings

\section{INTRODUCTION}

Evidence-based practice (EBP) has been originated from evidence-based medicine (1). It's requirement in the field of physiotherapy is increasing day by day and has been widely implemented in different healthcare departments (2,3). Evidence-based practice is "the punctilious, straight forward, and sensible utilization of contemporary prime evidence from research work in deciding procedure concerning the individual patient's supervision (4). Although, patient's beliefs, desires, ethics along with the working experience of the physiotherapist, furthermore requisites to be examined in deciding the procedure (4). However, implementation of evidence based practice (EBP) is tough and requires various policies that simplify the difficulties of organization of care, individual practitioners and varying healthcare cultures to be EBP environment (5). Implementation of EBP is needed to lessen the injuries due to insufficient utilization of knowledge among the practitioners (1). It has been seen that randomized controlled trials, case reports, scientific procedures like descriptive and qualitative research, also the expert opinion, case description charts, and scientific theories have led to the best evidences. The clinical execution needs to be led by the proved research findings along with the patient's values as well as clinical expertise. The research evidences must be updated with the new research results timely (5). The ruling aim of EBP is to provide high level of qualitative and rationalized care, and to improve patient result by choosing affordable and secure treatment (6). The term 'evidence' states high quality clinical re- 
search (7). The prime obtainable research finding must be from a high-grade research, however if in case, high grade clinical study isn't accessible then the foremost accessible research finding may comprise of low-grade clinical study, clinical expertise or solidarity views. Such practices should not be included into EBP (7). 'Practice knowledge' arises from professional practice and experience. During each patient encounter, knowingly or unknowingly, physiotherapists put on to their confidential knowledge base. However, the 'evidence' which is required for Evidence-Based Practice is not 'practice knowledge'. A satisfactory clinical judgment includes combination of high-grade clinical study, preferences of the individual (patient) as well as practice knowledge. Some more determinants such as cultural backgrounds of patients, regional factors etc. can also influence decision (7). However, even after lots of advancements in the field of healthcare system having EBP, there are various barriers which have been examined through various research surveys. The main barriers to EBP implementation are shortage of time, lack of ability to understand statistical data, insufficient employer assistance, less resources, low interest and lack of simplifying the final outcomes of the studies of patient, and sometimes lack of publication (4).

Till today, only few researches have been carried out considering the attitudes, behaviors and use of research findings among the healthcare professionals in clinical practices $(5,8,9)$. Therefore, the present study was undertaken to access the knowledge, attitude and implementation of EBP of physiotherapists in India via a cross sectional study.

\section{METHOD}

A cross sectional survey was conducted among the Indian physiotherapists from April 2020 to June 2020 during the COVID-19 lockdown period. The ethical clearance for the study was not taken because of the COVID 19 pandemic, as the meetings were suspended. Interns, post-graduate students, private practitioners, clinical practitioners in hospitals and professors in physiotherapy institutes were included in the study. Students undergoing bachelors of physiotherapy degree were excluded from the study.

\section{Data collection}

Data was collected through a web based customized questionnaire. Questionnaire included demographic information about the subjects and items for measuring the awareness of, attitude towards, knowledge of, barriers to and implementation of EBP. The questionnaire contained 5-point Likert-type scale $(1=$ strongly disagree, 2 = disagree, $3=$ neutral, $4=$ agree, and $5=$ strongly agree) and multiple-choice questions to assess the knowledge, attitude and implementation of evidence based practice.

\section{Sample size estimation}

mple size was calculated by using EPI software, percentage frequency was kept at $95 \%$ with $3 \%$ absolute precision and the sample size of 122 was calculated $(5,10)$. 137 responses were generated from a population of 300 .

\section{Data analysis}

Data was compiled and tabulated by software named Streebo and the tables and graphs for the responses were generated.

\section{RESULTS}

Out of 287 survey questionnaire forms, 137 forms were completed and returned back with a response rate of $47.73 \%$. Females had a higher participation with $59.10 \%$ response rate. The academic qualifications of the participants were bachelors (45.30\%), masters $(38.70 \%)$ and $\mathrm{PhD}$ $(16.10 \%) .36 .50 \%$ subject had their work setting in private clinics, $46 \%$ in hospitals and remaining $17.50 \%$ in academics. Out of 137 respondents, $63.50 \%$ subjects had an experience of 0-5 years, $23.40 \%$ had $5-10$ years and $13.10 \%$ had experience of 10 years and above. Only $40.10 \%$ respondents stated that they have taken some formal training in EBP. Approximately, 49.10\% mentioned that they were aware of term evidence-based practice (Table 1). The intention for developing knowledge and implementation, application and the barriers in implementing EBP are presented in tables 2-5. 
TABLE 1. Awareness regarding term EBP

\begin{tabular}{|l|c|c|c|c|c|}
\hline & Not true at all & Not really true & Possibly true & Quite likely true & Very true \\
\hline I understand what is meant by the term EBP & 16.80 & 14.60 & 25.50 & 21.20 & 1.90 \\
\hline I am aware of EBP in my profession & 12.40 & 23.40 & 21.20 & 21.20 & 1.90 \\
\hline $\begin{array}{l}\text { I am aware of current developments in EBP } \\
\text { in my profession }\end{array}$ & 16.80 & 14.60 & 16.80 & 29.90 & 1.90 \\
\hline
\end{tabular}

TABLE 2. Intention for developing knowledge and implementation of EBP

\begin{tabular}{|l|c|c|c|c|c|}
\hline & $\begin{array}{c}\text { No intention } \\
\text { at all }\end{array}$ & $\begin{array}{c}\text { Unlikely to } \\
\text { consider } \\
\text { doing it }\end{array}$ & $\begin{array}{c}\text { Could } \\
\text { consider } \\
\text { doing it }\end{array}$ & $\begin{array}{c}\text { Highly likely to } \\
\text { consider } \\
\text { doing it }\end{array}$ & $\begin{array}{c}\text { Absolutely intend } \\
\text { to do it/ keep } \\
\text { doingit }\end{array}$ \\
\hline I intend to develop knowledge about EBP & 12.40 & 19 & 29.90 & 21.20 & 17.50 \\
\hline $\begin{array}{l}\text { I intend to develop skills in accessing, } \\
\text { acquiring and appraising evidence relevant } \\
\text { to my area of practice }\end{array}$ & 12.40 & 23.40 & 21.20 & 21.20 & 21.90 \\
\hline $\begin{array}{l}\text { I intend to read relevant literature to } \\
\text { update knowledge }\end{array}$ & 13.60 & 20.80 & 23.20 & 18.40 & 24 \\
\hline $\begin{array}{l}\text { I intend to apply best available evidence } \\
\text { findings to improve practice }\end{array}$ & 13.60 & 20.80 & 23.20 & 24.40 & 24 \\
\hline
\end{tabular}

TABLE 3. Understanding about application of EBP

\begin{tabular}{|c|c|c|c|c|c|}
\hline & $\begin{array}{l}\text { Strongly } \\
\text { disagree }\end{array}$ & Disagree & Neutral & Agree & Strongly agree \\
\hline Application of EBP is necessary in my work & 0 & 0 & 100 & 0 & 0 \\
\hline Literature and research findings are useful in my day-to-day work & 12.4 & 25.5 & 21.9 & 21.2 & 19 \\
\hline I need to increase the use of evidence in my daily work & 21.2 & 21.2 & 21.9 & 21.2 & 14.6 \\
\hline $\begin{array}{l}\text { I am interested in learning or improving the skills necessary to } \\
\text { incorporate EBP into my work }\end{array}$ & 16.8 & 16.8 & 21.9 & 16.8 & 27.7 \\
\hline EBP helps me make decisions about clients in my work & 12.4 & 16.8 & 35 & 21.2 & 14.6 \\
\hline
\end{tabular}

TABLE 4. Implementation of EBP

\begin{tabular}{|l|c|c|c|c|c|}
\hline & Never & Monthly or less & Fortnightly & Weekly & Daily \\
\hline $\begin{array}{l}\text { Formulated a clearly answerable question } \\
\text { that defines the client or problem, the intervention and } \\
\text { outcome(s) of interest }\end{array}$ & 16.8 & 19 & 25.5 & 21.2 & 17.5 \\
\hline Searched an electronic database & 12.4 & 19 & 21.2 & 21.2 & 26.3 \\
\hline Integrated research evidence with your expertise & 16.8 & 19 & 21.2 & 25.5 & 17.5 \\
\hline Read published research reports & 16.8 & 14.6 & 29.9 & 21.2 & 17.5 \\
\hline $\begin{array}{l}\text { Informally shared and discussed } \\
\text { literature/research findings with others in your workplace }\end{array}$ & 16.8 & 19 & & & \\
\hline
\end{tabular}

TABLE 5. Barriers in implementing EBP

\begin{tabular}{|c|c|c|c|c|c|}
\hline & $\begin{array}{l}\text { Strongly } \\
\text { disagree }\end{array}$ & Disagree & Neutral & Agree & $\begin{array}{c}\text { Strongly } \\
\text { agree }\end{array}$ \\
\hline I want to learn new information & 16.8 & 16.8 & 26.3 & 21.2 & 19 \\
\hline I make time to read research & 16.8 & 16.8 & 21.9 & 16.8 & 27.7 \\
\hline $\begin{array}{l}\text { Insufficient time is one of the greatest barriers to the use of EBP in my clinical/ } \\
\text { professional practice }\end{array}$ & 13.6 & 23.2 & 19.2 & 28 & 16 \\
\hline $\begin{array}{l}\text { The cost of information resources limits my use of EBP in my clinical/ } \\
\text { professional practice easy access to computers dictates } \\
\text { whether or not I practice EBP }\end{array}$ & 21.2 & 21.2 & 26.3 & 16.8 & 14.6 \\
\hline
\end{tabular}

\section{DISCUSSION}

The result of the present study showed that only $43.1 \%$ respondents were aware of evidence-based practice in physiotherapy. However, Manjula et al.
(5) have shown that $49.1 \%$ of the respondents that included undergraduate and postgraduate medical students in North Karnataka were aware of the term evidence based practice and Gupta et al. (11), 
who studied on dentists of Bhopal, showed 70.5\% of the practitioner were aware of the term EBP. Weng et al. (10) suggest that there was an awareness of EBP in medical, nursing and pharmacological and allied healthcare professionals. The result of the present study showed that only half of the respondents were aware of the term EBP which is much lesser as compared to previous researches on evidence based practices. All of these suggests that there is greater need to increase the awareness regarding evidence based practice in physiotherapists of India. For this, there is significant need to inaugurate some workshops, seminars and conferences for generating awareness regarding EBP for physiotherapists practicing in India. Further, evidence based practice can also be included as a compulsory topic in the curriculum for the physiotherapy students so that they are well aware of this. The result also showed that evidence based practice is convenient and essential in their routine work and they should have positive attitude towards EBP. Almost half of the participants of the study intend to develop knowledge and implement EBP in physiotherapy profession. Similar inclinations of positive attitude was also suggested by Jette et al. (8) and have concluded that EBP lead to better quality of patient care and a satisfactory clinical judgment that includes combination of high-grade clinical study, preferences of the individual (patient) as well as practice knowledge. Some more determinants such as cultural backgrounds of patients, regional factors etc. can also influence decision (7). The present study showed that $26.3 \%$ of the participants were involved in regular access to databases for gaining and updating knowledge regarding the EBP which was considerably higher than the study conducted by Manjula R et al. (5), which was only $8.2 \%$. All of this is are suggestive of greater utilization of the web based resources by the students and professionals for reviving the new updates and information regarding EBP now a days. The students can further utilize the available resources more efficiently for attaining information explored by numerous researchers. One of the prominent barriers in availing knowledge on EBP is lack of time (44\%) which is consistent with the findings of Manjula $\mathrm{R}$ et al. (5) and Heiwe et al. (1). The other ruling barrier in attaining and implementing EBP was the cost of information resources. $34.4 \%$ of the participants suggest that the cost of gaining knowledge was considerably higher. Majority of the subjects were affirmative regarding EBP but did not have enough knowledge and expertise for its implementation. Curriculum in academics (particularly in India) is majorly built on theoretical knowledge \& textbooks and students are hence unable to gain any evidence based perspective to clinical settings. Therefore, there are substantial exigencies to develop a deeper insight for attaining knowledge, removing the barriers and implementing evidence based practices for physiotherapists practicing in India.

\section{CONCLUSION}

Physiotherapists need to upgrade their perspective, knowledge, understanding and skills regarding EBP. The authorities, administrators and the curriculum developers should consort with the various barriers that are hindering the EBP. It will be beneficial if initiatives are taken at both organizational and individual levels.

Furthermore, EBP must be added to the academic curriculum for the better recognition of evidence-based practice among the upcoming professional years in the physiotherapy sector.

and perceived barriers of Brazilian physical therapists from São Paulo state. Braz J Phys Ther. 2015;19(4):294-303.

5. Manjula R, Srivastava AK, Dorle AS. Evidence based practice: knowledge, attitude and practice among undergraduate and postgraduate medical students of a medical college in North Karnataka, India. Int J Community Med Public Health. 2018; 5:2411-5

6. Scholten-Peeters GG, Beekman-Evers MS, van Boxel AC, van Hemert S, Paulis WD, van der Wouden JC, et al. Attitude, knowledge and behaviour towards evidence-based medicine of physical therapists, students, teachers and supervisors in the Netherlands: a survey. J Eval Clin Pract. 2013;19(4):598-606. 
7. Herbert R, Jamtvedt G, Mead J, Hagen KB, Chalmers I. Practical Evidence-Based physiotherapy. 2nd ed. United Kingdom:

Butterworth-Heinemann; 2011.

8. Jette DU, Bacon K, Batty C, Carlson M, Ferland A, Hemingway RD, Hill JC,Ogilvie L, Volk D: Evidence-based practice: beliefs, attitudes, knowledge, and behaviors of physical therapists. Phys Ther. 2003;83:786-805.

9. Grimmer-Somers K, Lekkas P, Nyland L, Young A, Kumar S. Perspectives on research evidence and clinical practice: a survey of Australian physiotherapists. Physiother Res Int. 2007;12(3):147-61.
10. Weng YH, Kuo KN, Yang CY, Lo HL, Chen C, Chiu YW. Implementation of evidence-based practice across medical, nursing, pharmacological and allied healthcare professionals: a questionnaire survey in nationwide hospital settings. Implementation Sci. 2013;8:112.

11. Gupta M, Bhambal A, Saxena S, Sharva V, Bansal V, Thakur B. Awareness, Attitude and Barriers Towards Evidence Based Dental Practice Amongst Practicing Dentists of Bhopal City. J Clin Diagn Res. 2015 Aug;9(8):ZC49-54.

Conflict of interest: none declared Financial support: none declared 